\title{
Alas e luas brancas: gênero, performance e música em Chiquinha Gonzaga
}

\author{
Rafael do Nascimento Cesar ${ }^{*}$
}

\begin{abstract}
Resumo: Esta breve comunicação busca refletir acerca da trajetória da compositora Chiquinha Gonzaga (18471-1935) assim como algumas das estratégias narrativas mobilizadas por seus biógrafos depois de sua morte. E é rastreando as formas de objetivação de seu carisma a partir de suas biografias que se pode compreender de que forma as convenções de gênero estão articuladas à produção de bens simbólicos.
\end{abstract}

Palavras-chave: Chiquinha Gonzaga, gênero, biografia.

No dia 17 de outubro comemorou-se o Dia Nacional da Música Popular Brasileira. A lei que institui a data dentro do "calendário das efemérides nacionais"1 pode ser considerada como um pequeno, mas significativo, ato simbólico que assinala como patrimônio imaterial nacional um produto cultural específico e, ao mesmo tempo, confere-lhe uma guardiã, ou mesmo uma "mãe fundadora". Segundo o deputado Fernando Ferro (PT/PE), “A adoção desse dia é uma forma de homenagear a primeira maestrina do país, que, em pleno século XIX, quando predominava a música europeia nos salões da aristocracia brasileira, desafiou os costumes de sua época e ousou trazer os ritmos africanos para suas composições musicais"2.

De uma forma ou de outra, falar sobre Chiquinha Gonzaga é quase sempre falar em transgressão ou em algum tipo de ousadia heroica. Dentre os vários tipos de registros que pude consultar no tempo em que realizei esta pesquisa, a tônica ia muito frequentemente em direção de transmitir ao público leitor - ou ouvinte - uma característica pessoal da compositora que acabou por definir não somente seu modo de compor, mas também aspectos da dinâmica cultural brasileira do século XIX: o pioneirismo.

\footnotetext{
${ }^{*}$ Graduando em Ciências Sociais - USP.

${ }^{1}$ Lei №12.624, de maio de 2012.

${ }^{2}$ Extraído do site <http://www.chiquinhagonzaga.com/memoria/2012 dia nacional MPB.html>.
} 
Ao ser qualificada como pioneira, opera-se sobre Chiquinha Gonzaga um ato mágico que tem por objetivo desconectá-la de todo o substrato social e cultural que a enreda, fazendo com que esta passe a pairar livremente sobre um cenário que ora deleita-se ora enraivece-se com a intrepidez de seu caráter. Pioneira, Chiquinha Gonzaga inauguraria, com seu modo de ser, pensar e sentir, uma mentalidade inaudita e sem precedentes entre as mulheres e homens de sua época; algo que, por um lado, seria a razão última de seu reconhecimento e renome e, por outro, a maldição que a condenou a uma vida de sofrimento e incompreensão por parte de seus contemporâneos.

Nas cinco mais conhecidas biografias escritas sobre a compositora, o que chamei de "pioneirismo insuspeito" aparece em maior ou menor frequência e com maior ou menor ênfase, mas, de um modo geral, nenhuma delas escapa à transmissão deste modelo que tem por finalidade confirmar tanto a genialidade pungente da biografada quanto denunciar as mazelas de uma sociedade machista, maledicente e obtusa, que não estaria "preparada" para uma personalidade tão "a frente de seu tempo".

A pesquisa que realizei teve como principal objetivo a investigação de tal fenômeno de apropriação e construção simbólica a partir da trajetória social da compositora, instrumentista e compositora Chiquinha Gonzaga. Interessava-me saber, entre outras coisas, como o passado desta personagem foi produto de uma elaboração intensa, por parte tanto de seus biógrafos como de estudiosos da música brasileira, e de criação, isto é, de ordenamento e inteligibilização desta mesma trajetória a partir de critérios dados pelas condições políticas e intelectuais em curso da história nacional. A esta questão ligava-se outra: por que, à história das relações de gênero no Brasil (ou, se preferirmos, "história das mulheres" brasileiras) subjaz a noção de que só é possível falar na transgressão e ousadia de grandes mulheres e, em contrapartida, na submissão e subalternidade de mulheres ordinárias? No caso de Chiquinha Gonzaga, em especial, ela toda fora caracterizada como alguém cuja estrutura psíquica foi capaz de subverter os processos de inculcamento de arbitrários sociais - característicos de qualquer socialização humana - e, com isso, pôde empreender a patriótica e altruísta tarefa de conferir à música brasileira aquilo que, diacriticamente, é seu traço mais distintivo: sua qualidade de popular.

Não quero negar, entretanto, o protagonismo de Chiquinha Gonzaga, que, juntamente com outros indivíduos com os quais mantinha estreitas relações, transfor- 
mou efetivamente a realidade cultural carioca, sobretudo no tocante à música e ao teatro. 0 que pretendo, pelo contrário, é historicizar a atribuição deste pioneirismo por suas biógrafas e biógrafos, evitando, portanto, entendê-lo tal como ele se apresenta aos leitores. É inegável que parte do reconhecimento ambíguo que Chiquinha legou às gerações futuras se deveu ao fato de ela estar na dianteira de uma dinâmica social e cultural efervescente - bem se sabe que o Rio de Janeiro tornou-se famoso no século XIX, seja na literatura ou na própria historiografia, pela sua proeminência no processo de modernização do Brasil -, é duvidoso, contudo, que a compositora tenha se valido única e exclusivamente de si própria para chegar aonde chegou. É preciso, portanto, retraçar as condições sociais e históricas de tal "pioneirismo insuspeito", isto é, evidenciar como era possível para uma mulher de sua posição social e de sua época abandonar o lar, os filhos e se dedicar a uma profissão como a de compositora e "pianeira" nos cafés-cantantes do Rio de Janeiro, ainda que tais atitudes fossem alvo de uma depreciação moral aguda em certos estratos sociais.

É curioso que muita da atenção dada à personalidade de Chiquinha Gonzaga, e muita da tinta gasta em seu nome, concentrem-se em esmiuçar detalhes de sua vida pessoal e subsumi-los a uma espécie de crônica de suas desventuras, sejam elas amorosas, maternais, públicas, etc. Tanto foco à sua vida acabou por provocar uma disjunção entre compositora e obra - ou ainda, entre a mulher e a música - colocando, assim, a vasta produção gonzaguiana sob um borrão luminoso e edulcorado o qual chamamos "fama". Reconhecidos pela "transgressão" que representaram perante os ouvidos eruditos do Império, os choros, maxixes, operetas e lundus que Chiquinha Gonzaga compôs pouco parecem servir como um documento histórico interessante para se identificar as tensões e conflitos existentes em um momento da história da cultura brasileira erroneamente definido pela simples oposição entre "a música europeia" e os "ritmos africanos".

A antropóloga Mariza Corrêa, ao investigar a relação de esposas de antropólogos famosos (como Dina Dreyfus, casada com Claude Lévi-Strauss) com a hierarquia do trabalho acadêmico e o esquecimento a qual muitas delas foram sentenciadas, lança a noção de notoriedade retrospectiva enquanto "o modo como o renome adquirido a partir de um certo momento pode iluminar a vida inteira de um persona- 
gem" (2003, p. 21). Dito de outro modo, tal noção age como se o prestígio e a fama de alguém, materializados sob o seu nome próprio, pudessem operar de maneira retroativa, fornecendo uma coesão e um sentido a toda a sua existência. A partir daí, nome torna-se então renome e passa a ser revestido de um brilhantismo e de uma singularidade que, olhando-se bem, sempre estiveram magicamente lá.

Ora, se o "efeito mágico" do nome próprio, - Chiquinha Gonzaga - produtor de uma "curiosa contaminação de prestígio para tudo e todos que gravitam ao seu redor" (PonTES, 2011, p. 235), pode, por um lado, colocar em posição de evidência uma dada figura humana, exultando algumas de suas características e feitos, faz encobrir, por outro, com a mesma facilidade, arestas angulosas e obscuras a respeito de sua trajetória. Trata-se sempre de um fenômeno parcial cujas pretensões à totalidade muito se lhe aspiram e nunca se efetivam. Tido como a instituição que assegura a constância e a unidade da identidade do sujeito através do tempo, o nome próprio sobressai-se enquanto obra, descolando-se de seu próprio portador e obliterando, assim, as diversas posições tomadas por ele em diferentes etapas de sua trajetória ao longo do espaço social e, também, mascara as motivações e incoerências de ordem subjetiva que o inspiraram a tais decisões.

O primeiro fato a chamar minha atenção, assim que me dirigi ao corpus empírico desta pesquisa, consistiu em observar como tal notoriedade retrospectiva era acessada a todo o momento pelos biógrafos de Chiquinha Gonzaga. Nas cinco obras que consultei, os autores escreviam partindo do pressuposto indiscutido (ao menos em seus livros) de que "Chiquinha Gonzaga" - este nome tornado renome - consistia ela própria numa obra acabada: a impressão primeira, que depois tentarei converter em hipótese, era a de que sua "história de vida" - suas experiências, suas motivações e frustrações - formaram-lhe uma personalidade tal que, descuidadamente, foi transferida desde a sua infância até seus últimos momento, ou, em outras palavras, as características de mulher "vitoriosa" e "pioneira" estiveram presentes no momento de seu nascimento e a acompanharam durante toda a sua existência.

Sua biógrafa mais prestigiosa, Edinha Diniz, comenta sobre um curioso fato logo nas primeiras páginas de seu livro: "Aquela que mais tarde viria a ser conhecida como uma mulher de enorme audácia, a compositora Chiquinha Gonzaga, já veio à vida conhecendo o perigo e sabendo vencê-lo" (DINIZ, 2009, p. 23, grifos meus). Efeitos de retórica à parte, este excerto mostra que, ao que se seguirá nas demais páginas, o leitor deparar-se-á com um indivíduo cuja coerência de personalidade 
já saltava aos olhos logo ao nascer, preexistindo, portanto, à própria experiência de vida responsável por sua formação.

O fenômeno apontado por Mariza Corrêa, que ocorre com a pessoa de Chiquinha Gonzaga, encontra correspondência direta em relação a sua música. Todas as biografias procuram explicitar, cada uma a seu modo, que ela teve, desde sempre, uma inclinação inata ao piano e à composição. "Na manhã bonita e radiosa de 17 de outubro, nascia uma artista!" (1978, p. 17) escreve Geysa Bôscoli, seu sobrinho e também biógrafo. Devido à sua vivência em círculos musicais considerados populares - como entre os chorões - Chiquinha acabou incorporando em sua obra traços estéticos que mais tarde seriam definidos como pertencentes a um fazer musical estritamente brasileiro. E tal vinculação forte com a "música popular" - uma noção inexistente à época de Chiquinha, principalmente com a conotação que possui hoje - , a qual o Modernismo e outras correntes intelectuais tanto valorizaram, acabou fixando no imaginário coletivo a ideia de que Chiquinha Gonzaga traria consigo desde muito nova o ethos já consolidado de uma artista experiente que cria a partir, única e exclusivamente, de sua "plena espontaneidade" subjetiva, "livre de toda injunção que não a de seu próprio impulso criador" (PINHEIRo FILHo, 2008, p. 19), isto é, não conforme os constrangimentos sociais e as normas estéticas de uma época.

Pierre Bourdieu oferece uma contribuição metodológica importante à problematização da noção de história de vida. Segundo ele, a este termo subjaz o pressuposto de que a vida é uma história e que tal história é necessariamente o "conjunto de acontecimentos de uma existência individual" (1996, p. 76) destinado a produzir um todo coerente e, em certa medida, teleológico. 0 biografado torna-se, então, personagem de uma estória (aqui no sentido ficcional) cujo enredo faz-se inteligível e objetivo. As cinco obras escolhidas não escapam, respeitando-se as suas especificidades, a esta tendência "literarizante": as peculiaridades da vida de Chiquinha Gonzaga - sua socialização em uma família de prestígio do Rio de Janeiro, sua formação intelectual e musical, os relacionamentos polêmicos e a maternidade - ora são expressas como fatos episódicos de um drama pessoal ora eclipsam-se face à forte repercussão de sua música nos círculos de sociabilidade popular da capital imperial. Em suma, elas tornam-se meros obstáculos a serem transpostos pela obstinação intrépida de sua personalidade "forte e pioneira".

No entanto, não quero dizer aqui que as biografias são "enganosas" ou que se afastem da "verdade" sobre a vida da compositora. Isto seria contraditório ao 
ponto de ferir meus objetivos na pesquisa. As aspas utilizadas procuram expressar a sensação de implausibilidade epistemológica que subjaz à tendência historicista de "voltar à informação inicial" (RANKE apud Elias, 2001, p. 18) como tentativa de fazer o "registro fiel dos eventos". Sabe-se que isso foi amplamente discutido pelas correntes contemporâneas da historiografia. Assim, ao contrário de basear-me em meu material empírico para "refazer os passos" de Chiquinha Gonzaga, procurei mapear os contextos de elaboração das biografias assim como as intenções dos autores, remetendo-os, portanto, ao momento histórico e intelectual em que foram escritos. E isto porque, a meu ver, o procedimento biográfico foi responsável não por traçar um quadro definitivo da compositora, mas sim por recriá-la: a cada obra, ela adquiria novas características e perdia outras, sempre de acordo com o autor que se dispunha a narrar sua vida ${ }^{3}$. No limite, portanto, a cada biógrafo coube contar sua verdade, contar segundo determinados critérios - e visando a determinados objetivos - sua versão dos fatos.

Assim sendo, pude perceber que mais coube aos propósitos de elaboração de algumas das biografias mostrar a relevância de Chiquinha Gonzaga na música popular brasileira, algo que, ainda no final da década de 1930, era fenômeno muito pouco estudado. Já para outros autores, o estudo da história de vida de Chiquinha não vem subsumido ao estudo de sua obra e da relevância desta para o patrimônio cultural brasileiro, mas sim carrega o intuito de expor ao público as desventuras de uma personagem singular, esmiuçando detalhes íntimos de sua existência.

Em suma, todos os autores tiveram sua fração de responsabilidade numa espécie de "invenção" da biografada, cujos parâmetros são definidos segundo critérios encarregados de oferecer-lhe uma coerência sempre exterior, isto é, que é obra dos próprios biógrafos. A partir da leitura destes textos, pude perceber que é impossível atribuir um sentido único, pautado sobre qualquer tipo de critério, a uma vida. Toda forma de narrá-la é dar-lhe uma coerência $a d$ hoc, uma teleologia tangível somente aos olhos daquele que se debruça sobre ela - seja ele o próprio biografado (no caso da autobiografia) ou não.

\footnotetext{
${ }^{3}$ Um exemplo interessante é a questão do feminismo. Seus biógrafos insistem em associar Chiquinha Gonzaga ao movimento feminista, seja, mais uma vez, na condição de "pioneira" - "a primeira feminista brasileira" - seja como aquela que anteciparia historicamente a emergência do mesmo, sendo chamada de protofeminista. 0 fato é que, durante o século XIX, o feminismo inexistia, no Brasil, enquanto movimento político organizado, com pautas que tratassem exclusivamente da condição feminina e das assimetrias de gênero. Contava somente com algumas manifestações de cunho sufragista disseminadas em pontos esparsos do país.
} 
Portanto, meu "cuidado metodológico", no que se referiu ao tratamento do material empírico, se dá precisamente por saber que ele próprio já é fruto de uma interpretação sobre o objeto, e justamente por isso, diz respeito a uma visão parcial da realidade do mesmo, ou ainda, norteia-se mediante um determinado recorte. Não digo com isso que minha interpretação suplantará qualquer parcialidade, situando-se naquele âmbito de uma ciência objetiva isenta de quaisquer juízos de valor. Isto, como se sabe, há tempos vem sendo colocado em xeque pelos pesquisadores das ciências humanas. Ao contrário, portanto, os pontos relevantes por mim selecionados corroboram também com motivações assumidamente subjetivas, mas quis, contudo, perspectivar tais escolhas de acordo com a leitura de outros materiais. No limite, só existe parcialidade. 0 interessante é que todo o "biografar", ao menos nos moldes em que se pautaram as cinco obras, escapa por definição à objetividade, justamente por enfatizar as ações de um único indivíduo, por só dar atenção a ele e relegar ao patamar da "circunstância" o seu exterior.

O problema, contudo, residia nos próprios limites do corpus empírico da pesquisa. Como não me foi possível recorrer a documentos e fontes primárias, a reconstrução da trajetória social de Chiquinha Gonzaga só se efetivaria utilizando-se das biografias, o que nos remeteria novamente às questões colocadas. Era necessário, portanto, adotar outra estratégia: percebi que, apesar de todos os biógrafos tocarem em pontos comuns acerca da vida da maestrina, as biografias mais antigas continham visões muito discrepantes das mais recentes, tanto nos conteúdos que abrangiam quanto na forma de retratá-los. Isso me pareceu claro em outro comentário de Edinha Diniz logo na apresentação de seu livro: "Seus dois biógrafos anteriores [Lira e Bôscoli] retransmitiram, ou criaram, versões moralizadoras, que encobriam mais que revelavam", (DINIZ, 2009, p. 11). Ora, por que a disparidade de "versões", uma vez que se tratava da mesma pessoa? A quais causas se devem versões mais ou menos moralizadoras?

Dessa forma, as orientações e críticas de cunho metodológico realizadas na pesquisa, que são o objetivo desta comunicação, permaneceram em um plano teórico que buscou problematizar as fronteiras entre historiografia e ficção na tentativa de saber até que ponto tal disparidade era fruto não do método e dos documentos escolhidos, mas sim do posicionamento social e moral do biógrafo.

Era necessária, então, a elaboração de um modelo que evitasse a reprodução desta "narrativa romanceada do outro", utilizando, ao invés de "história de vida", a 
noção de trajetória: uma "série de posições sucessivamente ocupadas pelo mesmo agente [...] em um espaço ele próprio em devir e submetido a transformações incessantes" (BouRdiEu, 1996, p. 71). Ao invés de restringir o escopo da análise somente no que toca a existência individual de Chiquinha, e tentar compreender o conjunto de fenômenos subjacentes a ela exclusivamente a partir da mesma e de seus arredores (família, amigos, etc.), será preciso investigar o desenvolvimento de processos sociais em curso paralelamente à investigação de sua trajetória, indo além, portanto, de uma visão circunscrita. Parafraseando Bourdieu, é preciso realizar o mapeamento preciso dos espaços de possíveis pelos quais Chiquinha Gonzaga transitou e se posicionou, evidenciando, por um lado, todo um conjunto de valores simbólicos envolvidos na construção de seu habitus nessa sociedade específica (principalmente na relação entre a "mulher" e o fazer artístico) e, por outro lado, delinear quais foram os constrangimentos que condicionaram suas escolhas (conscientes ou não) no campo da produção musical.

Para tanto, seria preciso pensar a trajetória da compositora sempre em relação aos limites do campo musical carioca do fin de siècle e ater-se às suas leis próprias a fim de se compreender a inserção de Chiquinha dentro dele, a escolha de suas parcerias, o estilo de compor, o gênero dileto, etc. Assim, evito entender sua trajetória como algo dissociado das relações sociais objetivas e dos grupos interdependentes aos quais ela esteve associada ao longo de sua carreira profissional, como se ela simplesmente se sobrepusesse a tais numa atitude mecânica (um simples "pano de fundo" colocado no horizonte de qualquer situação objetiva), e busco compreender como o espaço social de sua época - entrecortado por instituições cortesãs tradicionais ao mesmo tempo em que experimentava novos modos de sociabilidade engendrados pelos ares da modernização oitocentista - forneceu as condições de concretização de sua música, ou, antes disso, forjou disposições e esquemas mentais de intelecção da própria música.

Partindo, portanto, do objeto da pesquisa - a trajetória social de Chiquinha Gonzaga e as inflexões de gênero presente na relação desta com o campo musical carioca oitocentista - pôde-se auferir que o sucesso da compositora, entendido aqui como a capacidade de galgar um reconhecimento tanto perante seus pares quanto 
perante determinadas frações de um público ouvinte, deveu-se a condições sociais internas inerentes a sua formação e ao acúmulo de altas quantidades de capital simbólico (econômico, cultural e social) e, também, a injunções externas dadas principalmente pelo processo de modernização sociocultural pelo qual passava a cidade do Rio de Janeiro no tocante à criação de novos nichos de sociabilidade e à reconfiguração da estrutura de oportunidades e expectativas de mulheres de determinada classe social frente ao mercado de bens simbólicos. Obviamente, não se pode prescindir das características psicológicas de Chiquinha Gonzaga no entendimento de suas atitudes combativas em relação a certos papéis a ela endereçados (por exemplo, o de esposa e mãe), no entanto, fixar-se nelas como único modo de explicar sua trajetória é operar uma disjunção entre o indivíduo e as relações sociais que o formam e que são, ao mesmo tempo, formadas pelo ele, recaindo, portanto, numa explicação misteriosa dos "nexos históricos" (EliAs, 2001).

Também consta como resultado da pesquisa o fato de que, ao compor e tocar suas próprias peças musicais em ambientes considerados "inadequados para uma mulher", Chiquinha Gonzaga interpela conceitos normativos operantes na sociedade carioca no tocante à divisão das esferas do público e do privado/doméstico em relação a homens e mulheres estabelecendo uma oposição binária. A tentativa de rastrear tanto as origens históricas quanto a lógica deste pensamento - que tem seu fundamento na oposição entre natureza e cultura e a associação da primeira ao feminino e da segunda ao masculino - constitui-se, na verdade, como argumento contra a ideia simples de que a música seria refratária ao feminino, apostando, assim, que a atividade musical (entendida aqui enquanto as habilidades de compreensão da linguagem musical, execução de instrumentos e composição) se articula com gênero de uma maneira difusa cujos significados são variáveis e móveis.

\section{Referências}

BôscolI, G. (1978). A pioneira Chiquinha Gonzaga. Natal, Departamento de Imprensa.

BouRdieu, P. (1996). “A ilusão biográfica”. In: Razões práticas. São Paulo, Papirus.

CorrêA, M. (2003). Antropólogas e Antropologia. Belo Horizonte, Ed. UFMG.

Diniz, E. (2009). Chiquinha Gonzaga: uma história de vida. Rio de Janeiro, Jorge Zahar. 
EliAS, N. (2001). A sociedade de corte. Rio de Janeiro, Jorge Zahar.

LIRA, M. (1978). Chiquinha Gonzaga: grande compositora brasileira. São Paulo, FUNARTE.

Pinheiro Filho, F. A. (2008). Lasar Segall: arte em sociedade. São Paulo, Cosac Naify. Pontes, H. (2011). Intérpretes da Metrópole. São Paulo, Edusp.

Recebido em novembro/2012

Aprovado em janeiro/2013 